\title{
Radiation Public Health Emergencies, Community Resilience, and the Role of Nuclear Medicine Technologists
}

\begin{abstract}
A
ssumptions for public health emergency preparedness planning involving the detonation of an improvised nuclear device in a large metropolitan area include casualties in the hundreds of thousands, total infrastructure damage within a radius of $0.8-4.8$ $\mathrm{km}(0.5-3 \mathrm{mi})$, and radioactive materials contaminating thousands of square kilometers ( $(I)$. It is apparent that responding to an improvised nuclear device detonation would require an unprecedented national effort. Hundreds of thousands of people would require (and many others would likely desire) monitoring for external and internal contamination with radioactive materials.
\end{abstract}

\section{See page 223}

Large numbers of people would need decontamination. Vast environmental areas would require surface monitoring for radioactive contamination and subsequent decontamination. The response and recovery efforts would take years. Although an improvised nuclear device scenario is the most extreme example, radiation public health emergencies can take many forms. Conversely, the key principles for responding to such events are similar.

One focus of public health emergency preparedness is building community resilience, which has been defined as the sustained ability of a community to withstand and recover from adversity (2). In March 2011, the

Received Jun. 27, 2013; accepted Jun. 27, 2013.

For correspondence or reprints contact: Adam C. Pomerleau, National Center for Environmental Health, Centers for Disease Control and Prevention, 4770 Buford Hwy. NE, MS:F58, Atlanta, GA 30341.

E-mail: von9@cdc.gov

Published online Aug. 5, 2013.

COPYRIGHT (C) 2013 by the Society of Nuclear

Medicine and Molecular Imaging, Inc.

DOI: 10.2967/jnmt.113.128447
Centers for Disease Control and Prevention published a document outlining 15 public health preparedness capabilities intended to serve as national standards that state and local public health departments can use to advance their preparedness planning (3). Two of these capabilities, community preparedness and community recovery, highlight various functions contributing to community resilience. A few of these functions include building community partnerships to support health preparedness; engaging with community organizations to foster public health, medical, and mental/behavioral health social networks; and coordination of training or guidance to ensure community engagement in preparedness efforts. In the context of a nuclear or radiological public health emergency, these functions can extend to the community of nuclear medicine technologists (NMTs).

NMTs already have essential skills necessary for the response to a radiation public health emergency. The use of radiation detection equipment, performance of radiation surveys of persons and the environment, and performance of radiological decontamination are all skills that will be needed on a large scale. NMTs can also assist with communication of risk; familiarity with radiation terminology and effects are vital for informing the public and providing just-in-time training to radiation-naïve responders. Response efforts after an improvised nuclear device detonation will be delayed because of many barriers (e.g., severe infrastructure damage and sheltering in place to protect from fallout), and communities will need to be self-sufficient, drawing on locally available resources and personnel, during the initial phases of a response. NMTs can be an effective part of the response and increase community resilience if properly engaged and integrated into public health planning for radiation emergencies.
In their article in this issue of Journal of Nuclear Medicine Technology, Van Dyke et al. present results from a study of NMTs highlighting the value of this untapped human resource (4). They surveyed members of the Technologist Section of the Society of Nuclear Medicine and Molecular Imaging regarding their knowledge of and access to radiation detection equipment, willingness to participate in the response to a radiation public health emergency, familiarity with current zpreparedness guidance tools, and participation in volunteer response organizations. Importantly, the results show that although NMTs are willing to respond to radiation emergencies, and have appropriate knowledge, they are largely unaware of available public health preparedness resources and few are currently working with response organizations.

There are several resources that NMTs can use to engage the emergency preparedness and response process. The radiation emergencies Web site (http:// emergency.cdc.gov/radiation) of the Centers for Disease Control and Prevention contains toolkits and information NMTs can access for guidance about emergency planning. Additionally, the National Center for Environmental Health is exploring the development of toolkits specifically designed for an NMT audience and the targeting of NMTs for additional training on emergency response activities to boost their incorporation into the public health enterprise. Lastly, by volunteering with local radiation protection agencies, the medical reserve corps, or other response organizations, NMTs can increase their participation in public health activities and enhance emergency preparedness. The Web portals of the Conference of Radiation Control 
Program Directors (http://www.crcpd.org) and Medical Reserve Corps (http://www. medicalreservecorps.gov) are good starting points to find contact information for those wanting to volunteer.

\section{DISCLOSURE}

No potential conflict of interest relevant to this article was reported.

\section{DISCLAIMER}

The views expressed are those of the authors and do not necessarily represent the views of the Centers for
Disease Control and Prevention or the Agency for Toxic Substances and Disease Registry.

\section{Adam C. Pomerleau \\ Armin Ansari \\ Charles W. Miller}

Radiation Studies Branch

National Center for Environmental Health

Centers for Disease Control and

Prevention

Atlanta, Georgia

\section{REFERENCES}

1. Executive Office of the President. Planning guidance for response to nuclear detonation. 2nd ed. http://www.epa.gov/radiation/docs/er/ planning-guidance-for-response-to-nuclear-detonation2-edition-final.pdf. Published June 2010. Accessed July 17, 2013.

2. Plough A, Fielding JE, Chandra A, et al. Building community disaster resilience: perspectives from a large urban county department of public health. Am J Public Health. 2013;103:11901197.

3. Centers for Disease Control and Prevention Web site. Public health preparedness capabilities: national standards for state and local planning. http:// www.cdc.gov/phpr/capabilities/DSLR_capabilities_ July.pdf. Published March 2011. Accessed July 17, 2013.

4. Van Dyke ME, McCormick LC, Bolus NE, Pevear J III, Kazzi ZN. Radiological emergency preparedness: a survey of nuclear medicine technologists in the United States. J Nucl Med Technol. 2013;41: 223-230. 